\title{
FROM "MODELS" TO "REALITY", AND RETURN. SOME REFLECTIONS ON THE INTERACTION BETWEEN SURVEY AND INTERPRETATIVE METHODS FOR BUILT HERITAGE CONSERVATION
}

\author{
F. Ottoni ${ }^{\text {a* }}$, F. Freddi ${ }^{\text {a }}$, A. Zerbi ${ }^{\text {a }}$ \\ a Dept. of Engineering and Architecture, University of Parma, Parma, Italy - (federica.ottoni, francesco.freddi, \\ andrea.zerbi)@unipr.it
}

KEY WORDS: Survey methodologies, Cultural heritage Conservation, Masonry structural analysis, Empiricism, Numerical Models

\begin{abstract}
:
It's well known that more and more accurate methodologies and automatic tools are now available in the field of geometric survey and image processing and they constitute a fundamental instrument for cultural heritage knowledge and preservation; on the other side, very smart and precise numerical models are continuously improved and used in order to simulate the mechanical behaviour of masonry structures: both instruments and technologies are important part of a global process of knowledge which is at the base of any conservation project of cultural heritage. Despite the high accuracy and automation level reached by both technologies and programs, the transfer of data between them is not an easy task and defining the most reliable way to translate and exchange information without data loosing is still an open issue. The goal of the present paper is to analyse the complex process of translation from the very precise (and sometimes redundant) information obtainable by the modern survey methodologies for historic buildings (as laser scanner), into the very simplified (may be too much) schemes used to understand their real structural behaviour, with the final aim to contribute to the discussion on reliable methods for cultural heritage knowledge improvement, through empiricism.
\end{abstract}

\section{INTRODUCTION}

1.1 The interpretation of the structural behaviour of historic masonry buildings: an open issue

Historic buildings are the complex result of craft and inconsistent procedures, which architectural changes and different construction phases, in addition to degradation phenomena on materials and time effects, have strongly modified during centuries. Most of times, these changes are not easily quantifiable (Roca, 2004).

Moreover, the behaviour of the masonry itself is extremely complex: in masonry buildings, in fact, the resistant structure is substantially unknown; because its lack of resistance to tensile stress, in fact, there is not adequate diffusion of stress states in the structure and thus only a part of this same structure really reacts.

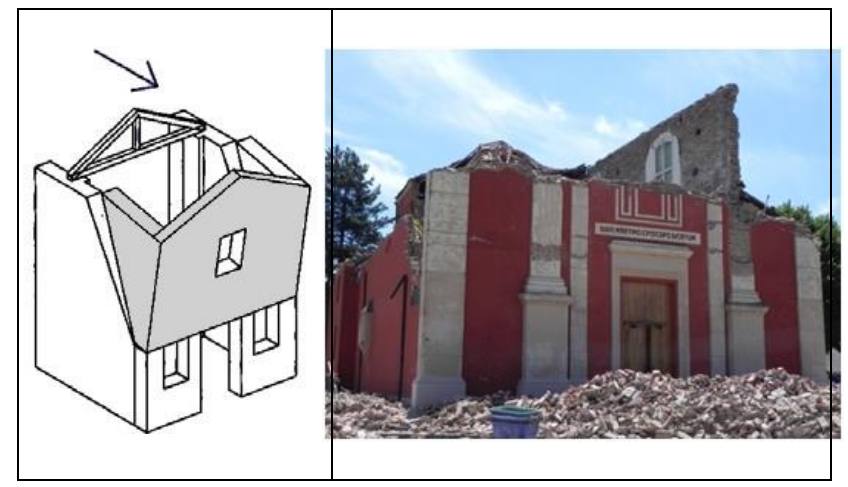

Figure 1. The evidence of "local mechanism" during an earthquake: on the left, the mechanism of façade turning, and on the right the evidence of this mechanism after the strong Emilia Romagna earthquake (May 2012).

It's well known from literature (Giuffrè, 1982; Giuffrè and Carocci, 1993; Lagomarsino, 2006), and it has been formalized by the recent Italian law in the field of cultural heritage structural conservation (Direttive, 2011) that ancient masonry structures do not show a "global behaviour" but - for the presence of cracks and physiological partialization - they can be rather divided in macro-elements, each showing quite independent behaviour. This phenomenon is fully evident in case of earthquake (Fig.1).

Numerical models used so far are not yet able to simulate such a complex behaviour with an acceptable accuracy, especially in case of buildings with a complex history. Unfortunately, huge numerical models of even large historical buildings are still used today, showing results really divorced from the real structural behaviour of monuments; in most of cases, they pretend to apply modern calculation methods to the whole $3 \mathrm{D}$ model of the historic building directly achieved after the preliminary survey operations, without any critical assumption in the middle.

In fact, despite the high accuracy and automation level reached by survey technologies and numerical analysis programs, the transfer of data between these two accurate modelling languages is not an easy task and the most reliable way to translate and exchange information without data loosing is still

Corresponding author 
to be defined. It's a matter of fact that, especially in the last years, very accurate methodologies and automatic tools are available in the field of geometric survey and image processing and their fundamental role in the field of cultural heritage knowledge and preservation it's well known (Logothetis et al., 2015). The same holds for numerical models used for ancient building structural analysis: very smart and precise codes are continuously improved in order to simulate the mechanical behaviour of masonry structures (Tomasoni and D'Ayala, 2011).

The research, in both cases, is concentrated in improving the accuracy of these important instruments, in order to create virtual replicas, as identical as possible to historic buildings, which can be able to simulate, quantitatively and in detail, their real structural behaviour. Unexpectedly, most of times, what we need is the inverse process, and the real challenge is rather to understand how we can "reduce" the accuracy and the number of information we can gather on cultural heritage, in order to reliably analyse and better comprehend - almost qualitatively - its real behaviour: we can call this process "from the models to reality and return". Starting from some real examples, this paper will present the results of this process in some interesting cases, which can help in clarifying this open issue.

\section{FROM COMPLEX MODELS TO REALITY THROUGH MONITORING: A VAULTED CASE}

\subsection{The case of Sala Verdi in Parma}

The first case here presented is the analysis of a XIX century pavilion vault which covers the Sala Verdi of the Conservatorium in Parma (Italy). The geometry of this great vaulted room is complicated by its organization into regular nails - three on the short sides and eight along the long ones which are abutted on the central lowered profile barrel vault (Fig.2).

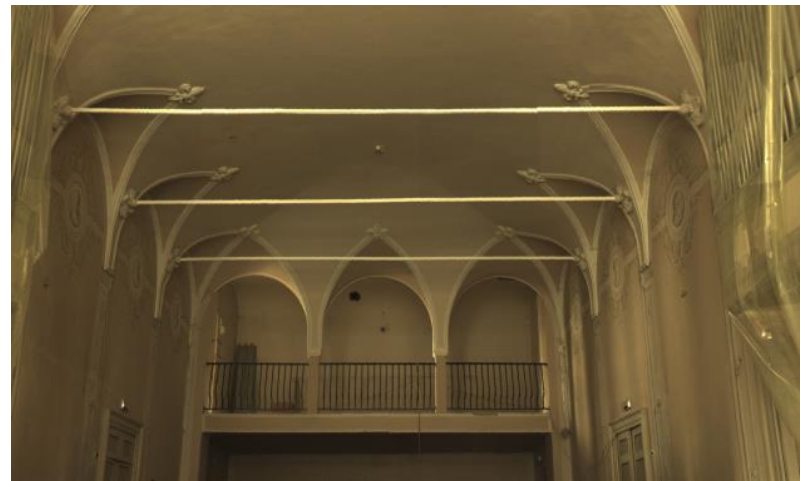

Figure 2. The nailed and lowered profile pavilion vault which covers the Sala Verdi of Conservatorium, in Parma (Italy)

Largeness and disposition of passing and non-passing cracks, variously distributed on the main longitudinal walls of the pavilion and on the vault itself, have been analysed, coupled with the survey of the degradation of materials.

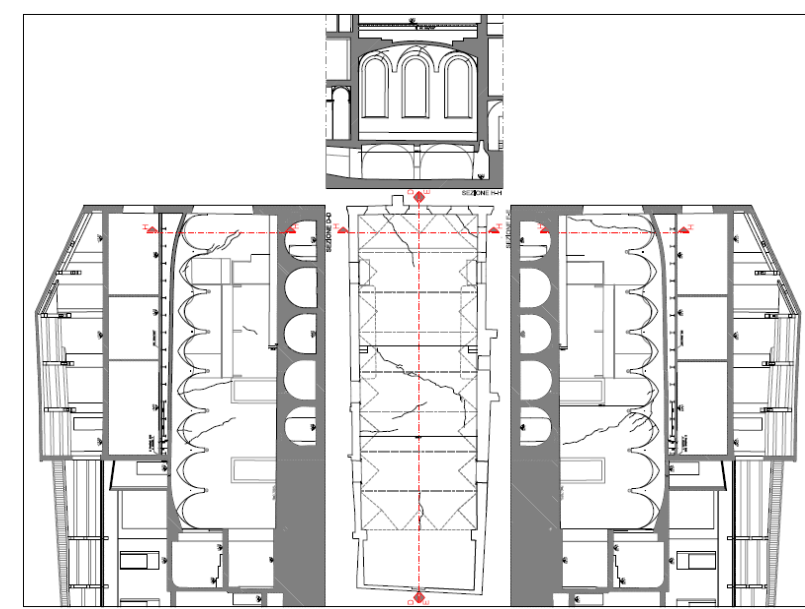

Figure 3. Scheme of the crack pattern of the great vaulted hall.

A map of these cracks has unravelled a shape which seems to be only partially consistent with the collapse mechanism typical of vaulted structures, though it has shown the well known lowering of the top of the vault mainly due to its own weight (Fig.3).

Somewhat, the series of inclined cracks along the two longitudinal walls seemed to be imputed to a differential settlement of the northern part of the hall: in particular, two main inclined cracks prosecute the main one which cuts the vault transversally, and other major cracks are present in the northern nails and on the longitudinal walls, just near the northern corners of the room, letting hypothesize a mechanism of collapse actually compatible with a differential settlement of the north wall.

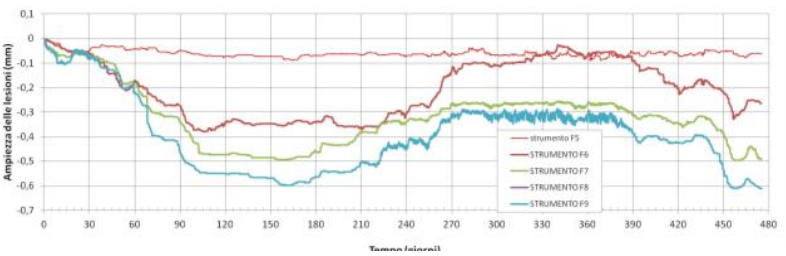

Figure 4. Trend of the four instruments installed in Sala Verdi: on $\mathrm{x}$ axis time (days) is plotted and on y the crack width (mm).

Indeed, a precision monitoring system (Fig.4) has been installed on the main cracks of the vault and the underlying structures, in order to achieve more precise information on their amplitude and global trend, also considering seasonal variations. In particular, 4 digital deformometers (F1-F4), temperature integrated, wireless, were installed since March 2012, each registering crack width and temperature data every six hours. Moreover, in November 2016 the instrument inserted on the vault was repositioned on the west-north wall, in order to better understand the possible differential settlement of the northern part.

While it was reasonable to hypothesize that the very lowered profile of the vault could have produced a considerable thrust on the longitudinal walls, the lack of evident physiological cracks along the longitudinal direction of the vault (at the expectable hinges) suggests that this has not happened and the analysis of cracks has allowed to hypothesize the differential settlement as the main cause of the surveyed damage of this structure. Nevertheless, the great thrusting vault represents the 
characteristic structural element of this part of the building and it's evident its deformation, with a lowering of its top. For this reason it was interesting to better investigate the geometry of this vault, in order to understand if this lowered curvature is due to deformation.

\subsection{The precision survey to investigate deformation}

In order to better comprehend this structure and to fully understand its damage mechanism, an accurate geometrical survey has been carried out, as the first step for detailed analysis. In virtue of their continuous advancements, digital survey techniques are now known to offer robust and realistic methods for adequately surveying heritage assets, and most notably laser scanning can provide very accurate base models for further investigations.

As the focus of the research was to investigate the vaults geometry, the laser scanner was set to survey above its horizontal line of sight. The instrument adopted was a Leica Scan Station C10, time of flight scanner, integrated camera.

Therefore, all the details of the vaults have been captured and two laser scanner, positioned in two points along the longitudinal axis of the room, enabled to capture almost all details of the vaults above, based on their curvature. The overlapping of the two set of data ensured details of vault curvature and the registration process produced good results. In total, they collected information on about 120 million points.

Recording the full 3D geometry of the vaults was straightforward by scanning from different stations (Fig.5).

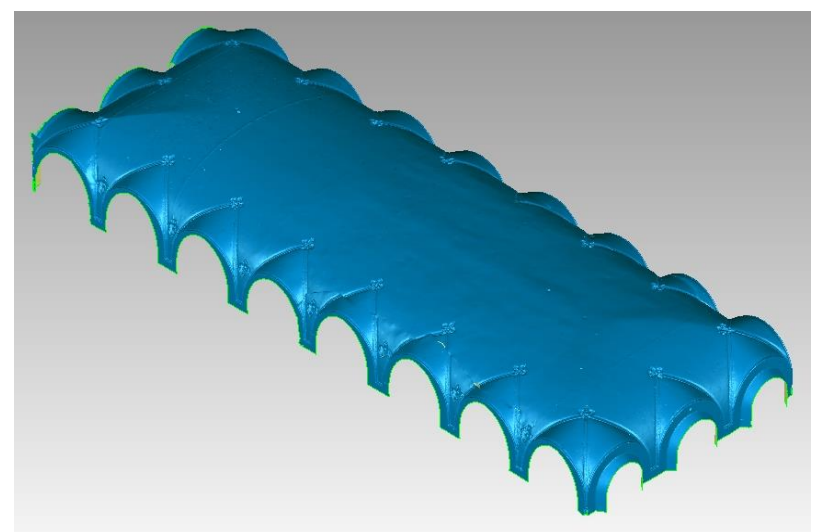

Figure 5. The 3D geometrical model

The two clouds were registered by Leica Cyclone 9.1 software, and they evidenced millimetre errors, thus quite acceptable.

The registration process produced good results and the overlapping scans produced detailed point cloud models, which were therefore exported with homogenized point density, in order to create more slender (and usable) files. It has to be stressed that, even after this operation, the level of detail obtained was sufficient to trace vault profiles very accurately. However, for the next processing, mesh models have been used, rather then the points clouds for vault curvature tracing.

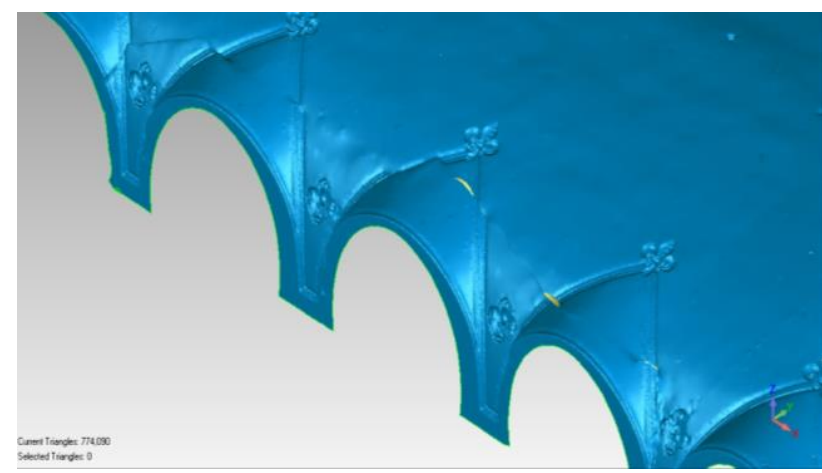

Figure 6. The voids (or "shadows") in the laser scanner model

Despite fully satisfactory for surveying the vault surfaces and the decorative apparatus, laser-scanning operation has to be carefully planned, particularly when, as in this case, some areas in the scene cannot be properly registered. In this case, the some obstacles, as the two organs on the north side of the longitudinal walls, and the complex geometry of the vault, represented by the nails, have generated some voids in the resulting cloud model, generally referred to as "shadows" (Guidi et al., 2014). In the final geometrical model of the hall, a number of "areas of shadow" were found, approximately on the intersection of the lateral nails with the pavilion vault, and, obviously, in the northern part of the longitudinal wall, beyond the organs.

In particular (Fig.6), these voids are detectable in the central six nails on the longitudinal sides of the hall (three for each side), and in the portions of vaults in between them.

For this kind of study, a precise survey can be used at two distinct scales: the first one, more important in this case, is aimed at documenting the curvature of the vault, in order to fully understand its original geometry and the consequent deformation occurred on it during time. A second scale of investigation, less interesting for the scope of the present study, could consider precise details of modelling profiles, in order to study decorative apparatus of the building: this second scale requires more accuracy, and even measures of some millimetres can be considered significant. Anyway laserscanner technique provides an accurate record of the built structure at large and more detailed scales.

Given the primary scope of this research, the information on the vault curvature was achieved by tracing along intrados, lines using the point of cloud model. We have to notice that the standard deviations, inevitable in this procedure, can be considered acceptable, considering the large span of the examined vault. As the goal of the study was to investigate the relation between vault deformation and possible collapse mechanism, in order to understand the primary cause of the damage, a further file with only some cut plane have been plotted, in order to better understand the deformation on the vault referred to the hypothesized mechanism of differential settlement towards north direction (Fig.7). 


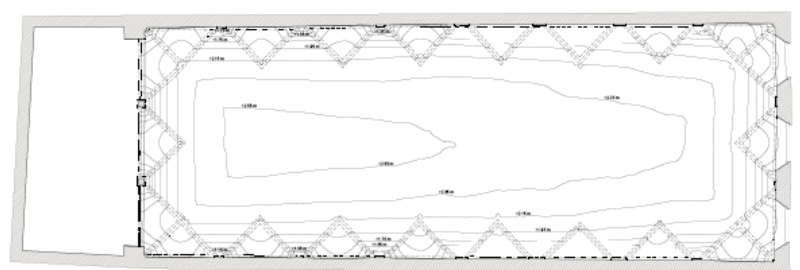

Figure 7. Level curves of the vault: north side on the right

We will see that this simple graphical elaboration, together with the classic longitudinal section of the hall, more than accurate and snappy refined 3D model, can give, almost in this case, an interesting interpretative key of the main global movement of the vault, if properly coupled with the result of monitoring and numerical model analysis of the monument.

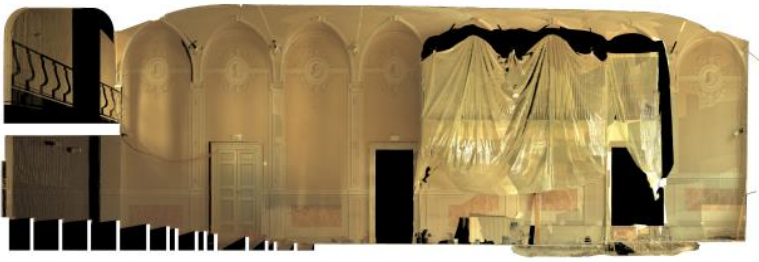

Figure 8. Longitudinal section of the vault, achieved by the laser scanner survey

However, digital surveying and modelling techniques represent a fundamental starting point for any further step in the rigorous investigation of this vaulted room, enabling to reach its current geometry.

\subsection{The structural model: from survey to abstraction}

Therefore, in order to investigate the structural behaviour of the vault, a simpler 3D model of the hall has been drawn, starting from the more precise laser-scanner processing, by eliminating the voids ("shadows") and by purifying the geometry from those dimensional variations, in the vault curvature, reliably attributable to the presence of decorative apparatus.

Then, the surfaces of the model were smoothed and cleaned and the geometry has been completed under the two organs, on the northern side of the longitudinal walls. After these operations, a corrected surface has been reconstructed and discretized by triangles (Fig.9).

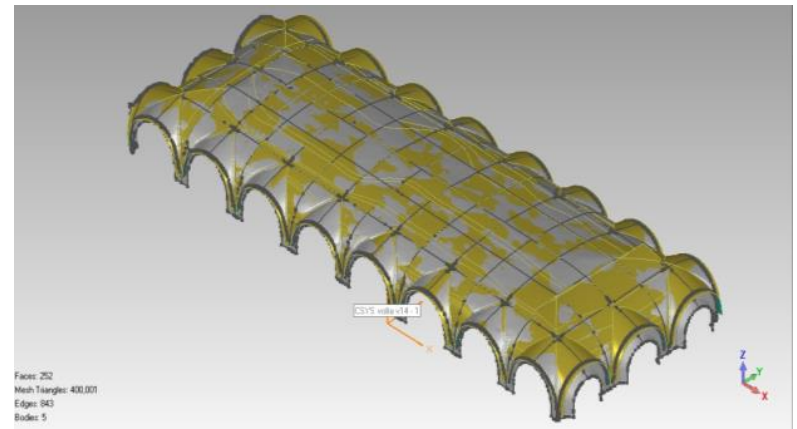

Figure 9. Reconstruction of the surface, discretized by triangles

Therefore, the vault has been modelled through a discretization by shell-type elements (Fig.10), considering a vault thickness of $15 \mathrm{~cm}$. Given the strong irregularity of the surveyed geometry, it was not possible to apply solid elements, which could have generated unacceptable material incongruences after the extrusion operation.

Here the values applied to the FEM model:

Specific weight: $1750 \mathrm{~kg} / \mathrm{m} 3$

E (Young modulus): $5500 \mathrm{MPa}$

Poisson coefficient: 0.15 .

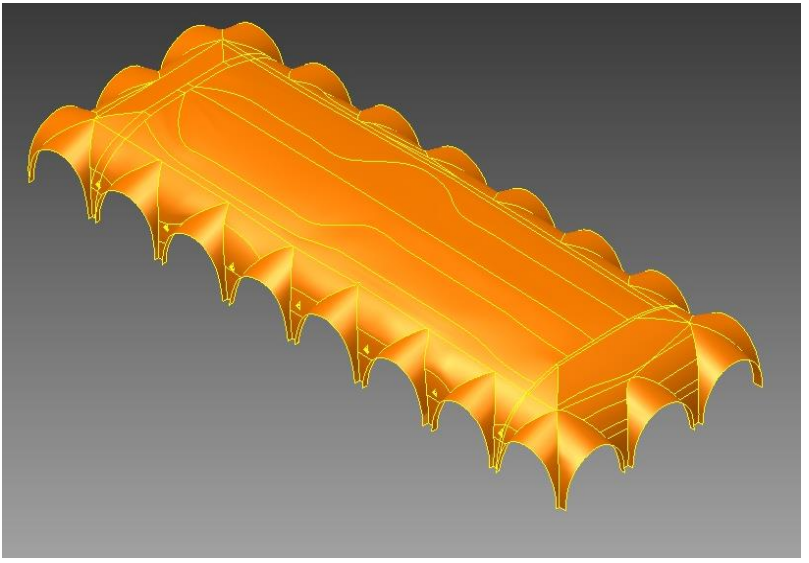

Figure 10. The FEM model of the vault

In order to correctly simulate the structural behaviour of the vault, the perimeter walls have been inserted at the impost through elastically yielding constraints which actually simulate the stiffness of these elements. Moreover, minor stiffness conditions have been inserted along the two short sides (south and north wall) in order to reliably take into account the different boundary conditions: three slender small columns on the south side and a slender external wall with three wide openings on the north side. Moreover, the existing tie-rods (seven, installed between two consecutive nails along the transversal section of the barrel vault) have been inserted in the model, as achieved by the survey.

This model has been then used to simulate the real load conditions of the structure, considering the vault subject to its own dead weight and to the filling at the extrados $(1500 \mathrm{Kg} / \mathrm{m} 3)$ supposed to be present from the impost plane to the hinges and at the intersection of the vault with the perimeter nails.

As predictable, the model has shown the favourable effect of this filling material on the vault structural behaviour: in fact it considerably reduces the stresses at the impost, against with a minimum of weight gain over the vault.

Thanks to the experimental tests carried out on some samples taken from the vault, it had been possible to determine the mean compressive strength of masonry, which resulted around 5.5 MPa; while, for literature (Como and Lanni, 1993) is conceivable a minimum value of tensile strength for masonry. 


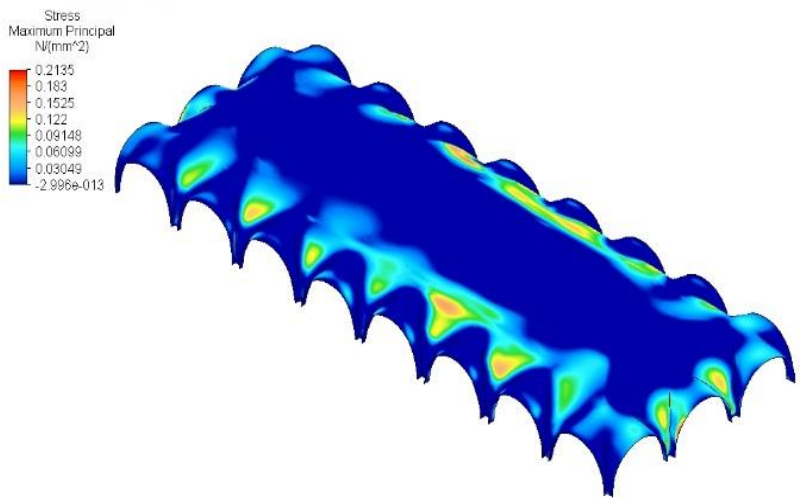

Figure 11. Total $\sigma_{11}-$ principal stress values

After processing, the model evidenced for this structure the classical behaviour of masonry vault, with major deformations, as predictable, on the top of vault and generally less than 1.3 mm (limited after all, considering the vault span), unless some irregularities due to the considerable lowering on the northern part of the vault itself, as strongly evidenced by the geometrical survey (Webb et al., 2016.). Also the maximum stress values are acceptable in relation to the mean strength capacity of the material, both at the intrados and at the extrados of the vault (mean values are around 0.15-0.18 MPa) and the compressive stresses are always under $1 \mathrm{MPa}$, thus far away from the material strength capacity. Some peaks are imputable more to unrealistic deviations on the geometrical model (inevitable with this level of information accuracy) rather then to real state of stress (Fig.11).

\subsection{Monitoring as interpretative key}

The complex analysis path carried out on this vault, coupled with the monitoring data of the last four year has finally confirmed the collapse mechanism hypothesis.

Indeed, monitoring systems are really efficient to evaluate the real behaviour of historical structures, once correlated with the results obtained by advanced numerical models and precise survey processing. If it's possible to rebuilt these correlations for the entire period of history, every aspects of building behaviour can be reached, including creep phenomena, very significant in masonry structures. In the field of statics (or quasi-statics) monitoring, the first quantity to be measured is obviously the temperature, which notoriously produces sensitive deformations in masonry, daily and seasonal.

Thus, the crack width data, once purified from the temperature effects by applying well known correlation formulas (Ottoni et al., 2010), can give fundamental information on the real movements and deformations of structures, which, ones related with possible causes, can help in reconstructing the link between actions and structural response, which is usually the main goal of any knowledge process applied to cultural heritage.

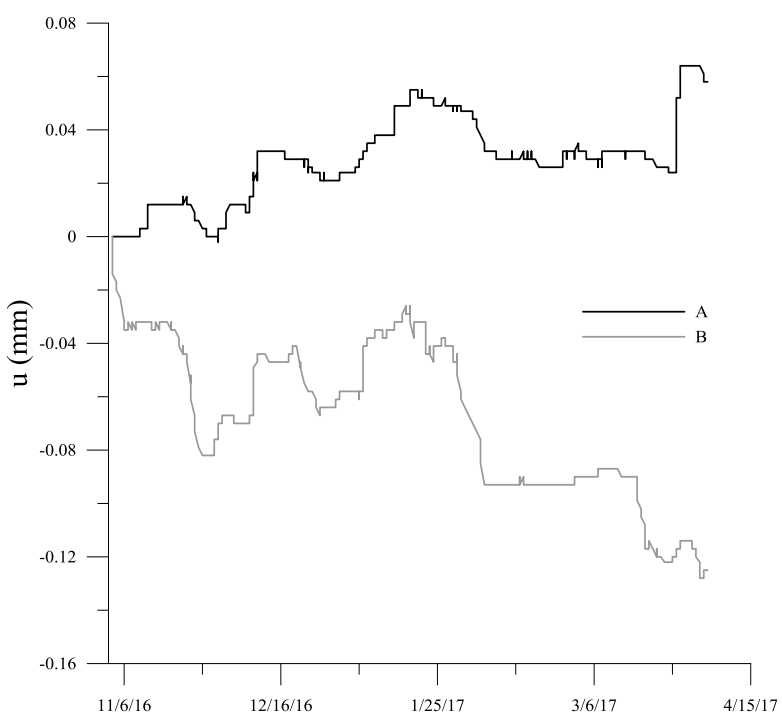

Figure 12. Crack width $(\mathrm{mm})$ of the two instruments installed on the two longitudinal walls (A west wall; B: east one), near the northern part of the hall.

In this case, thanks to a fusion between precision geometrical surveys, experimental investigations and numerical modelling, the static behaviour of the vault has been finally determined.

Indeed, by examining the data recorded by the two instruments installed on the inclined wide cracks which cut the longitudinal walls, near the northern part of the hall, it's possible to better understand the real consistency of the hypothesized (and partially surveyed) differential settlement of the northern wall. In figure 12 is plotted the relative behaviour of the two sides of the macro-element constituted by the northern portion of the Sala Verdi: while a differential settlement of this portion is confirmed, the plotted data show a rotation towards northwest direction of the northern wall. This analysis adds fundamental information on the real mechanism which actually involves the examined structure, leading to set up reliable strategy of structural restoration.

The model has been corrected in order to reliably interpret the reality, through the analysis of simple monitoring data, which have given fundamental clue on the real cause of damage.

This study then can be oriented to both gathering the input information and allowing later calibration or validation of results. The wide experiences acquired thanks to the structural monitoring systems which have been installed for years on many important historical buildings allow now to propose efficient procedures for the best design and use of these systems in order to preserve the architectural historical heritage.

The monitoring systems, indeed, if correctly designed and used, allow not only to control the possible evolution of pathological phenomena, but above all to reach a deep knowledge of the structural behaviour of the buildings and of their response to both normal and exceptional actions, thus being extremely useful for the preservation interventions.

\section{FROM REALITY TO SIMPLIFIED NUMERICAL MODEL: THE CASE OF CITADEL OF DAMASCUS}

The second case here presented is the analysis carried out on some structures of the ancient Citadel of Damascus (Syria), studied in 2008, in the field of a cooperation project (Syrian DGAM - Italian Ministry of Foreign Affairs): a central vaulted 
hall (the Ayyubbid Hall, Fig.13) and two towers at the northeasthern (Tower 8) and north-western corners (Tower 12) of the Citadel. these buildings unravelled complex structures, which has been significantly modified during the centuries (Ottoni et al., 2008).

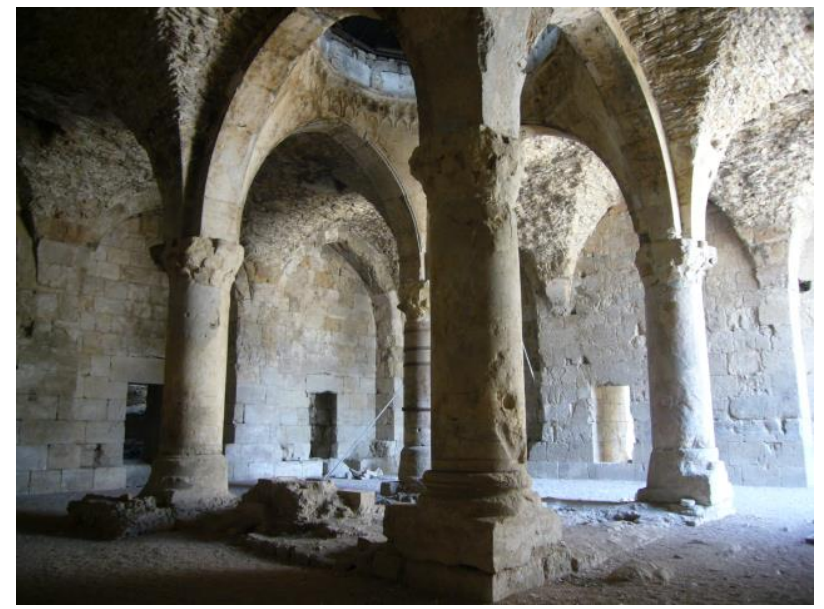

Figure 13. The great vaulted Ayyubidd Hall

A long path of historical analysis, precision geometrical survey, monitoring system, and experimental investigations have guided the numerical modelling of these three structures, allowing to determine their static behaviour and to plan some reliable conservation interventions. As already evidenced, numerical models can hardly describe the non linear mechanical behaviour of masonry, and they cannot gather, through such simplified numerical parameters, the consequences of historical events (partial collapses and reconstructions, floods, soil movements and degradations) occurred to ancient structures.

In this second case, the inverse process has been applied: once indentified the most probable collapse mechanisms of these different buildings, starting from the historical analysis and from the traces of past collapses reached also by geometrical survey, each complex structure has been reduced to simple isostatic scheme which has been solved and finally checked by FEM modelling. This match between abstract models and real behaviour has been possible only in virtue of a deep analysis of each sign on the buildings, considering also the results of the monitoring system installed on the structures.

\subsection{Searching for traces of the past: an accurate survey}

In order to assure the better results in the process of data acquisition for these three complex objects, survey operations have been organized by using different methods, strongly connected each other: direct method survey, topographic net and photogrammetry. A unique and traditional survey system cannot, in fact, guarantee satisfactory results, in order to get the complete 3D objects comprehension and the final aim of this procedure was to obtain accurate models, which, once simplified, could constitute an accurate base for further analyses. The interaction and superposition of the two survey methods, topographic and photogrammetric one, allowed to verify the survey result complete reliability.

The photogrammetric survey, leaned on the previous wide topographic network, permitted to integrate and extend all the topographical measures acquired in the three buildings, by determining a points cloud through which fixing the coordinates of each point of investigated structures (Roncella and Zerbi, 2008).

By applying this algorithm, every object planar feature has been correctly mapped in its corresponding position on the representation plane, regardless of its orientation: at the same time, in the same mapping frame elements not strictly coplanar or parallel are represented adequately. Moreover, dense 3D point restitution, using experimental automated algorithms (Structure from Motion based approach), has been performed in order to extract interesting sections and point cloud (Fig.14).

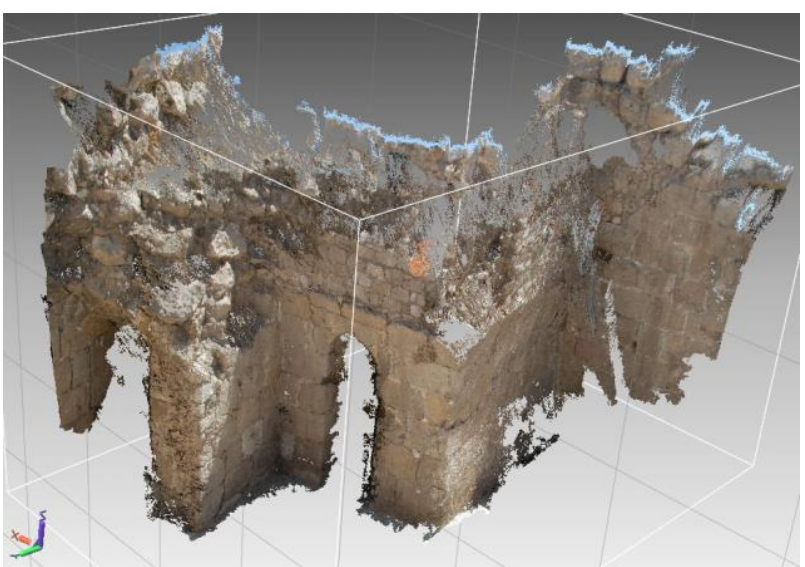

Figure 14. The point clouds obtained by the algorithm, at the upper level of Tower 12 .

Bi-dimensional drawings and 3D virtual models, have allowed, critically combined together, to deeply investigate these three monuments, accurately detecting any discrepancy from their original geometry, as reached by the historical analysis.

\subsection{Modelling and simplification}

After the survey of the geometrical organization of these buildings and the accurate mapping of their crack pattern it has been possible to reliably hypothesize the causes of their damage, in order to foresee their most probable collapse mechanisms. The Italian law in the field of cultural heritage structural conservation (Direttive, 2011) actually recommends to identify the most probable collapse mechanisms, considering the typology and the history of the building object of the static (and seismic) analysis.

On this empiric basis, the three structures have been reduced to abstract and very simplified models in order to interpret (and control) their reality.

Concerning the static aspects, the Ayyubbid Hall demonstrated a general good static state, which could be, nevertheless, strongly compromised after the scheduled demolition of the more recent building lying on its west side. This fact, coupled with the surveyed crack pattern of the hall (Fig.15), led us to reliably considering the possible rotation of one of the external walls, free under the vaults thrust and the seismic action, as the most probable collapse mechanism of the structure (Fig.16). 


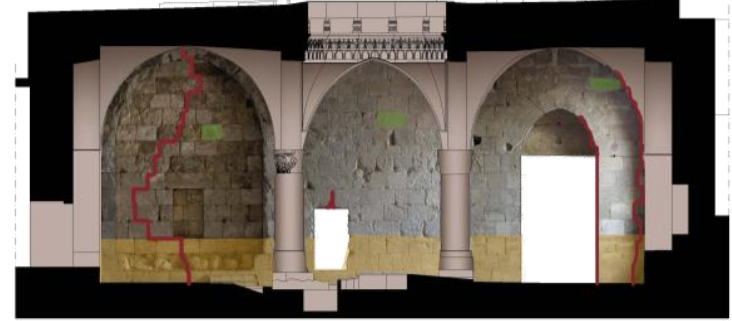

Figure 15. The crack pattern surveyed on the north internal wall of the Ayyubidd Hall

In this calculation we have considered the scheduled reduction of the filling on the extrados of the vaults for $90 \mathrm{~cm}$.

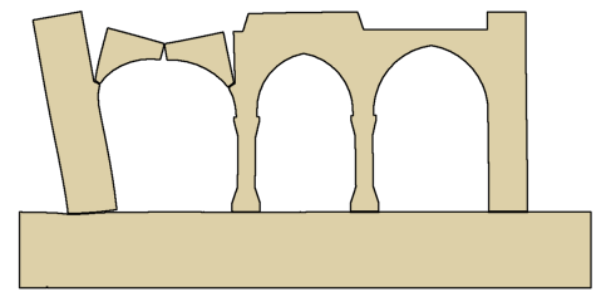

Figure 16. The hypothesized mechanism of collapse for the Ayyubbid Hall, with the 5 hinges typical of vaulted structures.

The 2D simplified model realized with the FEM code actually revealed the same mechanism, stressing the creation of natural hinges between the different elements, following the well known typical collapse mechanism of arches, which matched with the followed analytical path (Fig.17).
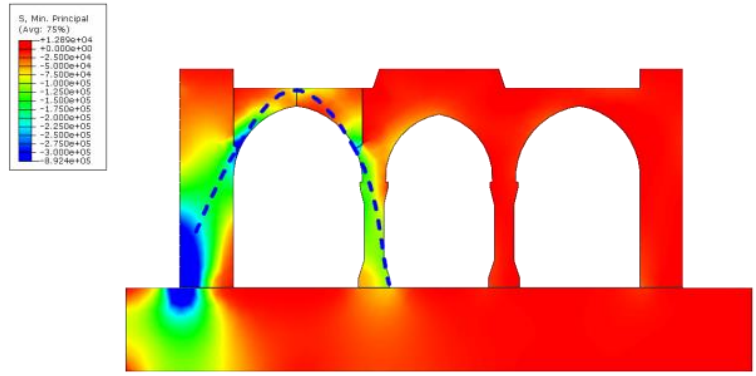

Figure 17. The results of the simplified 2D FEM model: principal stresses are plotted, which correspond to the hypothesized hinges.

The same simplified methodology has been applied to the Tower 8 in which the cracks, together with the results of the previous accurate geometrical survey (the progressive movement of the central pillar to the north and the identified drop toward North of the floors) allowed to identify the principal movement of the structure (Fig.18).

Also in this case, starting from the geometrical survey and the mapping of the crack patterns, supported by an in depth historical research, it has been possible to identify two main mechanisms which would synthesize the structural damage in this building: a capsizing movement of the north walls of the tower, mainly due to seismic actions, coupled with a general subside phenomenon of the soil (for the presence of the near Barada river, which flows on the north side of the tower).

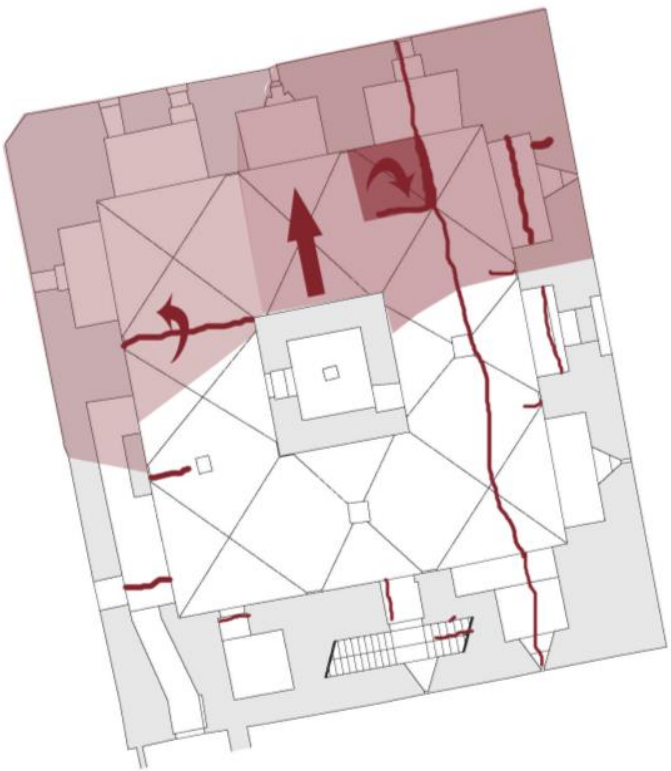

Figure 18. Scheme in plan of the main cracks and surveyed movements of the Tower 8: a rotation of the northern wall.

Indeed, the combined historical and geotechnical analyses carried out evidenced a vertical partitioning of the soil, due to the dead weight of the tower, increased in times by the progressive drop of the water table. The mechanical characteristics of the soil have been translated into the F.E.M. model in order to verify the effects on the structure of the hypothesized phenomenon. Moreover, as in the previous case of Ayyubbid Hall, a very simplified 2D model of the complex geometry of the building has been reconstructed in order to simulate the probable rotation of the external walls, subject to the double action of thrusts of the great vaults and conceivable future earthquakes. The simplified mechanism has been solved by using the equilibrium approach for the three superposed structure, working out step by step the reaction forces applied in the identified hinges on the horizontal planes and the model realized with the FEM code has revealed the same mechanism, stressing the creation of hinges at the same positions (Fig.19).
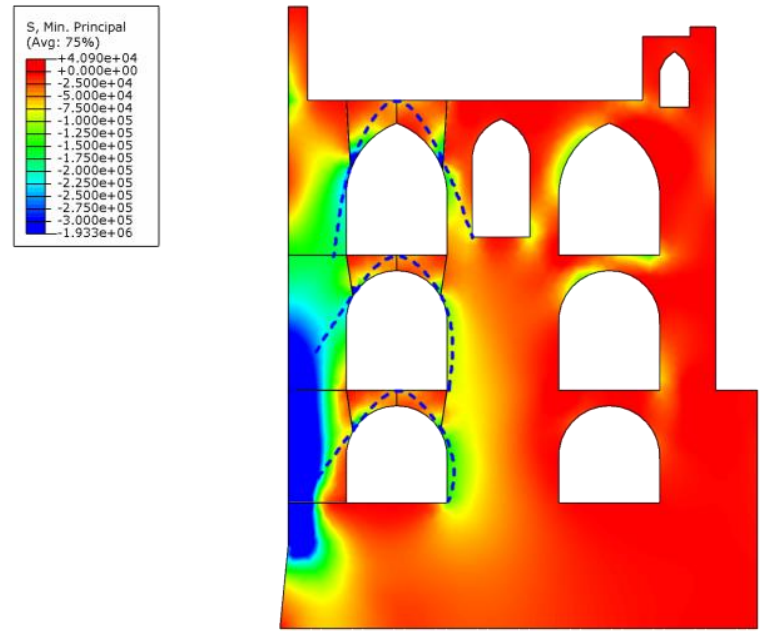

Figure 19. The results of the simplified 2D model 
In the analysis path applied on Damascus citadel, each building has been examined as if it were a prototype of itself, at realscale, subjected to a long-time experiment (since its construction to date).

Stated this, the best way to achieve their real structural behaviour was to "control the experiment", by the first accurate identification of their original shape, essentially through geometrical survey combined with historical analysis. On this bases, any architectural change and restoration intervention during times has been analysed, considering their most probable cause. In this process, the analysis of damage trends over time, mixed with other specific investigation (as soil behaviour and alteration) played a crucial role, leading to gather the buildings in their real static conditions.

The cause-effect relation, and, most of all, the real structural behaviour of these monuments has been directly understood by this process, more than by any complex virtual 3D modelling calculation: in other words, through knowledge, instead of proper construction science, which, however, has constituted the final check of the empiric-experimental method here applied.

\section{RETURN TO REALITY, THROUGH EMPIRICISM}

In spite of the important advances in structural analysis methods, masonry historical structures numerical analysis is still a challenging activity, due to the significant difficulties existing in reliably describing their complex geometry, history, materials and damage evolution. The use of the aforementioned methods in combination with advanced numerical models can represent powerful tools for the analysis of masonry constructions.

Although it is clear that accurate instruments and methods, which assure increasingly precise and numerous geometric information on historic buildings and which can implement complex structural calculation, are fundamental tools for improving the design process in restoration, this increasing of data need a specific and critical simplifying process, based on other competences (as history and static sense, mixed to empiricism) which will be able to create reliable conceptual model of buildings, starting from the virtual ones.

In this paper, two are the possible path followed to translate reality into reliable models.

The first one foresees the correction of the results of even refined and accurate numerical analysis by examining the evidence of real behaviour of the structures through their static (but even more dynamic) monitoring in time. This approach is not so different from the ancient master builders one; their main instrument was the experience and the direct observation of previous damages and collapse mechanisms and modern monitoring analysis starts from the same principle: only by observing the past mistakes we can correct them, and prevent further damages and collapses (Petrosky, 1994). If we choose to maintain the whole information in order to make precise numerical models $3 \mathrm{D}$, we have to correct the geometry and to reconstruct in some case the irregularity of the model, in order to analyse reliably the results in terms of stresses.

The second approach chooses to simplify at the beginning the redundant information of a very accurate $3 \mathrm{D}$ model of the structure, in order to better control the final results of the analysis. Even semantically, simplifying is not a easy operation and it needs to have clear the most probable mechanism of collapse which can involve different structures, following a typology-based approach, and to be able to foresee the expected results, almost qualitatively.

This is possible, once again, only in virtue of deep empiricism which is the first, and most effective guarantee of cultural heritage knowledge, and conservation.

\section{REFERENCES}

Barazzetti, L., 2016. Parametric as-built model generation of complex shapes from point clouds. In: Adv. Eng. Inform. 30 , pp. 298-311.

Brumana, R. et al., 2013. HBIM for documentation, Dissemination and management of built heritage. The case study of St. Maria in Scaria d'Intelvi. In: Int. J. Herit. Digit. Era 2(3).

Como, M., 1992. Equilibrium and collapse analysis of masonry bodies, Meccanica 27, pp.185-194

Como, M., Abruzzese, D., Lanni, G., 1995, Some results n the strenght evaluation of vaulted masonry structures. In: Proceedings of the architectural studies, materials and analysis STREMA. Computational Mechanics Publications, Boston, pp. $431-440$

Direttiva del Presidente del Consiglio dei Ministri (2011) Valutazione e riduzione del rischio sismico del patrimonio culturale con riferimento alle Norme Tecniche per le Costruzioni di cui al D.M. 14/01/2008.

Giannattasio, C., Grillo, S.M., Vacca, G., 2014, The medieval San Francesco convent in Cagliari: From the architectural, Materical and Historical Stratigraphical analysis to the information system. In: Int. J. Heritage Digital Era, 3(2), pp. 413-429.

Giuffrè, A., 1982. La meccanica nell'architettura: la statica. Nuova Italia Scientifica, Roma, Italy

Giuffrè, A., Carocci, C., 1993. Statica e dinamica delle costruzioni murarie storiche. In: Proc. CNR Int Congress "Le pietre da costruzione: il tufo calcareo e la pietra leccese", Mario Adda Editore, Bari, pp. 539-598

Guidi, G. at al., 2014. 3D survey and virtual reconstruction of archaeological sites, In: Digit. Appl. Archaelog. Cult. Herit., 1, pp. 55-69.

Lagomarsino, S., 2006. On the vulnerability assessment of monumental buildings. In: Bull Earthquake Eng. 4, pp. 445463.

Logothetis, S., Delinasiou A., Stylianidis, E. (2015) Building information modelling for cultural heritage: a review. In: ISPRS Ann. Photogramm. Remote Sens. Spat. Inf. Sci. 1, pp.177-183.

Magenes, G., Della Fontana, A., 1998, Simplified non-linear seismic analysis of masonry buildings, Proc. Br. Mason Soc., 8, pp. 190-195 
Ochsendorf, JA., 2002. Collapse of masonry structures. PhD thesis. Dept. of Engineering, Univ. of Cambridge, Cambridge, UK.

Oreni, D. (2013) From 3D Content Models to HBIM for Conservation and Management of Built Heritage, In: Computational Science and its Applications - ICCSA 2013, Springer Berlin, Heidelberg, pp. 344-357.

Ottoni, F., Coisson, E., Alejji, E., Blasi, C., 2008. Ancient citadel of Damascus, Syria:Analysis, Diagnosis and Monitoring for Conservation and Structural Consolidation. In: Proceedings of V International Conference of the Centre of Study in Arab Region, Responsabilities \& Opportunities in Architectural Conservation: Theory, Education and Practice, (ed. by Elwazani, S., Malhis, S., Al-Qawasmi, J).

Ottoni, F., Coisson, E., Blasi, C., 2009. Empiricism reappraisal in ancient buildings structural analysis. The masonry domes, from historical debates to numerical model. In: Proc. 13th Int. Conf. on Repair, conservation and strengthening of traditionally erected buildings and historical buildings REMO09, Wroclaw, Poland, pp. 197-206.

Ottoni, F., Coisson, E., Blasi, C., 2010. The crack pattern in Brunelleschi's dome in Florence. Damage evolution from historical to modern monitoring system analysis. In: Advanced Materials Research 133-134, pp. 53-64.

Petrosky, H., 1994. Design Paradigms. Case Histories of Error and Judgment in Engineering. Cambridge University Press, Cambridge.

Roca, P., 2004. Considerations on the significance of history for the structural analysis of ancient constructions. In: Proc. of $4^{\text {th }}$ Congress Structural analysis of historical constructions, Balkema, Amsterdam, pp. 63-73.

Roca, P., Cervera, M., Gariup, G., Pelà, L., 2010. Structural analysis of masonry historical constructions. Classical and advanced approaches. Arch. Comput. Methods Eng. 17, pp. 299-325

Roncella, R., Zerbi, A., 2008, The Topographic and Photogrammetric Survey as 3D Knowledge Instrument: the Case of Three Historical Buildings in the Ancient Damascus Citadel, Syria. In: Proceedings of CSAAR Conference, pp.531544.

Rossi P.P., Rossi C., 1998. Surveillance and monitoring of ancient structures: recent developments. In: Proc. of $1^{\text {st }}$ Int. Congress on Structural analysis of historical constructions SAHC1998, Barcelona, Spain

Tomasoni, E., D’Ayala, D., 2011. Three dimensional analysis of masonry vaults using limit state analysis wirth finite friction, Int. J. Arch Herit, 5 (2), pp. 140-171

Webb, N., Buchanan, A., Peterson, J.R., 2016. Modelling Medieval Vaults: Comparing Digital Surveying Techniques to Enhance our Understanding of Gothic Architecture, In: Proceedings of the $34^{\text {th }}$ eCAADe Conference, Volume 2, pp. 493-502. 